\title{
Are international partnerships important? Report of an experience
}

de Souza LR (1)

(1) Department of Tropical Diseases, Botucatu Medical School, São Paulo State University (UNESP - Univ Estadual Paulista), Botucatu, São Paulo State, Brazil.

Internationalization of Brazilian universities is widely discussed. Educational institutions and sponsoring agencies have been making efforts in order to promote the internationalization of research, including activities such as collaborative research, training of human resources and researchers' exchange, enabling foreign researchers to come to Brazil and vice-versa.

In Brazil there are many cooperation programs with the Ministry of Health, universities and foreign institutions, which provide varied opportunities for professors and researchers, in all areas of expertise.

Therefore, the internationalization of programs has been one of the scoring criteria in the triennial assessments of stricto sensu graduate programs, carried out by the Coordination for the Improvement of Higher Education Personnel (CAPES), a foundation linked to the Ministry of Education. These partnerships are fundamental to the consolidation of graduate programs in Brazil, with investments in human resources training within the country.

The promotion of international scientific cooperation aims to develop and implement research projects between foreign researchers. The exchange of knowledge, information, and experience is essential for individual and institutional growth.

According to a recent personal experience, it is worth to get to know different services and international researchers. On a visit to a French clinical research center, the Centre d'Investigation Clinique (CIC) there was an opportunity to promote cooperation work and the possibility of future exchanges. The center is associated with the Centre Hospitalier Universitaire Bichat-Claude Bernard in Paris, which belongs to the Public Assistance of France. I emphasize the great and friendly reception by the entire team with which I lived for a whole month.

The French center develops and performs clinical research protocols with a team of several professionals, such as doctors, nurses, biologists, engineers and others. They are responsible for the whole implementation, from identification to invitation of study subjects, with information about the research, informed consent forms, appointment scheduling, laboratory tests collection, medication intervention and if necessary, telephone contacts, filling of clinical report form (CRF) and quality control of the research.

The visit resulted in an invitation to participate in a multicenter protocol in Paris, recently started in the area of bacterial resistance. After the appropriate formalizations at the Botucatu Medical School of UNESP, as well as the approval of a sponsoring agency in Brazil, the research should begin by February 2013, following the same methodology adopted in France.

The whole experience, relatively easy to be 
implemented, was only possible because the head of the service went twice to France to previously discuss the partnership. The experience was highly positive, considering the short visit to a center that has been working with seriousness and competence for many years. Finally, the internationalization is a long and very difficult process, taking into account that the professors need to create and develop criteria for credibility among themselves.

\section{COPYRIGHT}

(c) CEVAP 2012

\section{SUBMISSION STATUS}

Received: October 30, 2012.

Accepted: October 30, 2012.

Full paper published online: November 30, 2012.

\section{CORRESPONDENCE TO}

Lenice do Rosário de Souza, Departamento de Doenças Tropicais e Diagnóstico por Imagem, Faculdade de Medicina de Botucatu, UNESP, Distrito de Rubião Jr., s/n, Botucatu, SP, 18618970, Brasil. Phone: +55 143880 1291. Fax: +55 14 3815 9898. Email: lsouza@fmb.unesp.br. 